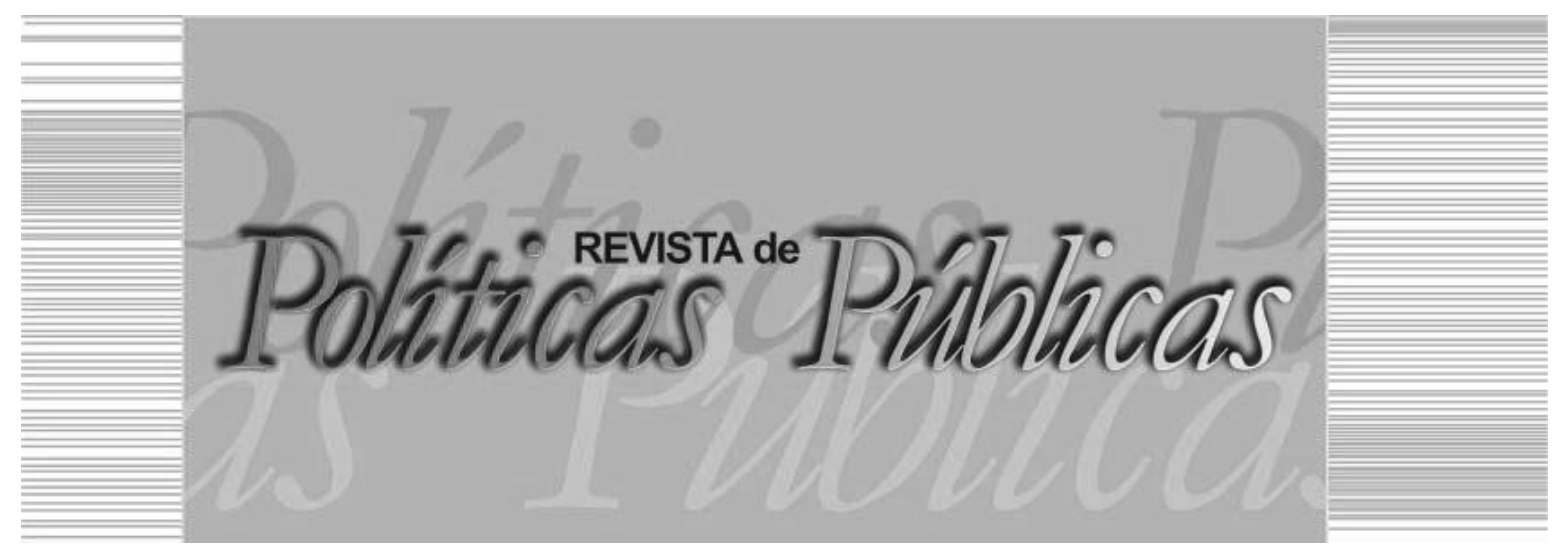

\title{
CULTURA, PATRIMONIALIZAÇÃO E DESIGUALDADE NO BRASIL E NA ÁFRICA AUSTRAL
}

\author{
Antonio Evaldo Almeida Barros ${ }^{l}$
}

\section{Resumo}

O artigo enfoca o Bumba-meu-boi do Maranhão, a Zulu Dance de Kwazulu-Natal, África do Sul e a Timbila de Inhambane, Moçambique e o universo social e cultural noqual estãoinseridos. Enfatiza as conexões entre patrimônio e educação, patrimônio e cidadania, Estado e cultura. Teórica e epistemologicamente, parte do reconhecimento de algo comumente olvidado: o fato de que África e os estudos africanos influenciaram o pensamento dos principais intelectuais e as formulações teóricas sobre as quais operam as Ciências Sociais eHumanas contemporâneas. Parte de pesquisabibliográfica e documental e se estrutura na interface entre estudos africanos, epistemologias do sule perspectivas da análise social que enfatizam, no estudo da cultura, questões referentes a mudanças, conflitos, contradições e desigualdades sociais. Entende que aprofundar estudos acerca de repertórios e produtos culturais, numa perspectiva comparativa ecruzada Sul-Sul, poderá contribuirpara compreensãodas relações entre Estado, Cultura e Políticas Públicas.

Palavras-chave: Cultura, patrimônio, desigualdade, políticas culturais, educação, cidadania.

\footnotetext{
${ }^{1}$ Licenciatura em História e Filosofia, Doutor em Estudos Étnicos e Africanos pela Universidade Federal da Bahia (UFBA), Professor Adjunto do Curso de Estudos Africanos e Afro-Brasileiros na Universidade Federal do Maranhão (UFMA) e Professor Adjunto do Departamento de História e Geografia da Universidade Estadual do Maranhão (UEMA). E-mail: antonioevaldoab@gmail.com / Endereço: Universidade Federal do Maranhão - UFMA: Centro Pedagógico Paulo Freire Coordenação do Curso de Estudos Africanos e Afro- Brasileiros, Térreo, Av. dos Portugueses, 1966 - Vila Bacanga, São Luís - MA. CEP: 65080-805; Universidade Estadual do Maranhão - UEMA: Cidade Universitária Paulo VI, Av. Lourenço Vieira da Silva, nº 1000 - Bairro: Jardim São Cristovão, São Luís - MA. CEP 65055-310.
} 


\title{
CULTURE, PATRIMONIALIZATION AND INEQUALITY IN BRAZIL AND SOUTHERN AFRICA
}

\begin{abstract}
This research focuses on the Bumba-meu-boi of Maranhão, the Zulu Dance of Kwazulu-Natal, South Africa and Timbila of Inhambane, Mozambique, and the social and cultural universe in which these repertories and cultural modalities are inserted. It emphasizes the connections between patrimony and education, patrimony and citizenship, state and culture. Theoretically and epistemologically, part of the recognition of something commonly forgotten: the fact that Africa and African studies have profoundlyinfluenced the thinking of the main intellectuals and the theoretical formulations on which the contemporary social and human sciences operate. Thus, starting from a bibliographical and documentary research, the work is structured in the interface between the African studies, the epistemologies of the south and perspectives of the social analysis that emphasize, in the study of the culture, the questions referring to the social change, conflicts, contradictions and inequalities. The deepening of studies about cultural repertoires and products, in a comparative and cross-South-South perspective, could contribute significantly to the understanding of the relations between State, Culture and Public Policies.
\end{abstract}

Key words: Culture, heritage, inequality, cultural policies, education, citizenship.

\section{INTRODUÇÃO}

Resultado de reivindicações de diversos setores sociais, particularmente, dos sujeitos envolvidos com sua produção, os bumbas do Maranhão receberiam, em 2011, do Instituto do Patrimônio Histórico e Artístico Brasileiro (IPHAN), otítulo de PatrimônioCultural doBrasil. Na perspectiva doIPHAN, oBumba-boido Maranhão constituiria um bem cultural de grande relevância para a história, a memória e a identidade do povo brasileiro. Em processo similar ao ocorrido com os bumbas da terra de O Mulato (1881), de Aluízio Azevedo, e de Os tambores de São Luís (1975), de Josué Montello, formas deZulu Dance, presente em tantos momentos da vida, como aqueles das comemorações e rituais - a exemplo dos funerais, de homense mulheres da África do Sul, como Madiba(Nelson Madela, 1918-2013), e de Timbila, um tipo de orquestra popular de Moçambique, cujos festivais não raro homenageiam as lutas de seus povos e líderes como Samora Machel (1933-1986), vêm sendo tomadas pelas políticas estatais e governamentais desses países como Patrimônio Cultural. 
Essas três modalidades e práticas de cultura características do sul do mundo, o Bumba-meu-boi do Maranhão, a Zulu Dance de Kwazulu-Natal, África do Sul, e a Timbila de Inhambane, Moçambique, e os universos culturais e sociais que lhes constituem e lhes são correlatos, são enfocados neste artigo. Do ponto de vista teórico e metodológico, a pesquisa ${ }^{1}$ da qual resulta este texto tem pretendido se estruturar na interface entre as discussões fomentadas a partir dos estudos africanos (BATES; MUDIMBE; O'BARR; 1993; ZAMPARONI, 2007), das epistemologias do sul (SANTOS; MENESES, 2009), da história social e da etnografia social relacionadas, por exemplo, a Edward P. Thompson e Max Gluckman, na medida em que estes autores tenham em comum a ênfase no estudo da cultura relacionada à mudança, aos conflitos e às contradições sociais.

Em primeiro lugar, esta pesquisa parte do suposto de que é preciso que se institua uma democratização epistemológica. Nas Américas, esta corrente de pensamento se relaciona, por exemplo, às filosofia eteologia da libertação latino-americanas (dentre os quais, é possível destacar Enrique Dussel, Walter Mignolo, Aníbal Quijano, Immanuel Wallerstein e Ramón Grosfoguel). Vários intelectuais africanos, como Appiah (1997), Mudimbe (1994, 1998), Mbembe (2001), Hountondji (1977)e Oladipo (2000) têm apontado para esta questão ou problemas similares. De fato, esta abordagem do campo dos Estudos Étnicos e Africanos é translocal e global, o que pode ser verificado com o trabalho de Linda Smith (2001) produzido no contexto australiano. Nesta perspectiva, entende-se que a discussão epistemológica das ciências sociais e humanas e da filosofia vem se pautando num modelo eurocêntrico que se pretende universal e imparcial, embora seja localmente gestado (eurocentrismo). O conhecimento e as práticas cognoscitivas e sociais produzidas são largamente baseados nesse paradigma, em que o outro é visto como um objeto e não como um sujeito que pensa. A América Latina e África estariam vivendo uma independência colonial, independência sem descolonização. Desse modo, dever-se-ia falar em colonialidade dopoder enãoemum mundopós-colonial.Eurocentrismoéaqui, essencialmente, o não considerar a possibilidade de construção de outros paradigmas, numa perspectiva em que as relações de saber-poder se dão do Sul em direção ao Norte, enão Sul-Sul. Fundamental para mudar essa situação seria democratizar a epistemologia. $\mathrm{O}$ que se busca, portanto, é um prisma localizacional: uma visão que lêosaber-poder nãohierárquica, mas heterarquicamente. Diantede 
um discurso homogeneizador, não se pretende propor uma antiglobalização, mas uma alter-globalização (um outro mundo é possível). Dessa forma, criticam-se fortemente aqueles tipos de multiculturalismo que vêem e qualificam as práticas e saberes dos setores populares, subalternos, negros, como folclore e tradição inerte e não como espaço de produção do saber. Desse modo, aceita-se que os Estudos Etnicos e Africanos necessitam relacionar, umbilicalmente, produção epistemológica e reivindicação política, produzir conhecimentos contribuindo para a descolonização das relações sociais e étnico-raciais. Trata-se de tentar contribuir para a descolonização de dentro de uma instituição que é vista, ela própria, como instituição da colonialidade do poder, a universidade.

Nessa perspectiva, érelevante destacar que as pesquisas realizadas sobre o continente africano têm levado a transformações no campo das ciências sociais e humanas. De fato, já faz algum tempo que se entende que, para levar a sério a história e as sociedades africanas, épreciso reconhecer que, emalgumas circunstâncias, determinados conceitos clássicos dessas ciências acabam não sendo pertinentes. Ora, a emergência dos estudos africanos, em geral, e da história da África, em particular, mudou, de modo profundo, o estatuto das ciências sociais e históricas e o lugar da Europa no mundo. Hoje, ovastoconjuntodas evidências sociaise históricas resultantes das pesquisas desenvolvidas no campo dos estudos africanos torna dificilmente defensável aideia de que processos sociais ehistóricos dos povos não europeus são resultado ou consequência das influências de um centro europeu dominante. Isto talvez seja desconfortável para aqueles que acreditam que a história consiste, por exemplo, na propagação, de modo único e unidirecional, de um modelo de civilização e desenvolvimento a partir de um centro identificado com a Europa ou o mundo ocidental, e mesmo para aqueles que entendem que a história resulta exclusivamente ou é totalmente determinada pelo sistema de exploração capitalista. (FEIERMAN, 1993).

Em segundo lugar, este trabalho se situa no campo das análises que relacionam os processos culturais às mudanças e transformações sociais. No clássico Análise de uma situação social na Zululândia moderna, publicado nos anos 1940, o africanista Max Gluckman (1987)ensinara que os próprios conflitos, contradições e diferenças entre os grupos sociais enum dado grupoé que constituiriam a estrutura a ser observada. Assim, entende-se que o estado normal da sociedade não é de solidariedade das partes, mas, sim, de contradição. 
Aquestão analítica, portanto, não seria de que modo a solidariedade éajustada e intensificada, mas de que modoé construída e mantida, acima dos conflitos e das contradições que constituiriam, estes sim, o estado normal das coisas.

Tudo indica que as ideias de Gluckman, e não apenas o materialismo histórico, influenciaram autores vinculados à História Social Inglesa, como Eric Hobsbawm que, nos anos 1940, participou de seminários de Gluckman, que o teria inspirado a escrever Primitive Rebels (1959) e Bandits (1972). Trata-se de pesquisas pioneiras sobre as chamadas formas arcaicas de rebelião, até então vistas como fenômenos marginais pelos estudos acadêmicos. (LÖWY, 2010). Enfocando os movimentos camponeses de resistência e protesto ao capitalismo, Hobsbawm $(1970,1976)$ argumentara que foi exatamente a aquisição de consciência política por parte dessas populações, especialmente as rurais, que tornara o século XIX o mais revolucionário da História.

Como lembraria Edward Palmer Thompson (1998), foram, em grande medida, os folcloristas do século XIX que separaram os costumes, as expressões culturais, de seus contextos de produção, $\mathrm{o}$ que lhes permitiu descrever tais práticas como simples manifestação da ignorância da população rural. Ora, ocampo da cultura constitui, muitas vezes, ocasião singular para se notar como os subalternos pensam e se situam no mundo. Muitos costumes e práticasculturais, alerta Thompson, têm uma função racional, não à toa muitos deles sãoreforçados pelos protestos populares. Além disso,éprecisoconsiderar que o termo "cultura", "[...] com sua invocação confortável de um consenso, pode distrair nossa atenção das contradições sociais e culturais, das fraturas e oposições existentes dentro do conjunto". Assim, "[...] uma culturaétambémumconjunto de diferentes recursos, em que há sempre uma troca entre o escrito e o oral, o dominante e o subordinado, a aldeia e a metrópole; é uma arena de elementos conflitivos". Apenas “[...] sob uma pressão imperiosa - por exemplo, o nacionalismo, a consciência de classe ou a ortodoxia religiosa predominante", a cultura "[...] assume a forma de um 'sistema". (THOMPSON, 1998, p. 13-21).

Finalmente, a análise aqui empreendida é metodologicamente balizada por um prisma comparativo. Um dos benefícios de uma abordagem comparada seria exatamente a possibilidade de preencher, em meio a hipóteses fundadas sob analogias, certas lacunas 
na documentação de um caso específico. (BLOCH, 1963). Evidentemente, embora significativas, as possíveis similaridades entre os universos sociais e históricos do Bumba-boi, Timbila eZulu Dance por si só não justificariam a elaboração de uma abordagem comparativa. O que torna significativo essa abordagem são os problemas que se podem levantar através dessa estratégia. Afinal, não éa especulação de que dois itens são comparáveis o que define um método comparativo, mas, sim, em que aspectos esses dois elementos são comparáveis. (LINDEN, 2003; HAUPT, 1998).

Esta pesquisa se desdobra em três eixos de investigação complementares. No primeiro, trata-se de, a partir de análise de documentos, sobretudo arquivísticos, analisar comparativamente a experiência histórica de múltiplos sujeitos que se empenharam em produzir os repertórios culturais nas diferentes regiões em foco. No segundo eixo, atenta-se para processos de revitalização da Zulu Dance, da Timbila e do Bumba-boi no contexto global contemporâneo; aqui, observa-seo modo como essas expressões socioculturais vêm sendotratadas em diferentes contextos doBrasil, Moçambique e África doSul, comoserelacionamcom as políticas estatais oficiais e com setores e atores globais; sua difusão através do mundo digital, particularmente, da rede mundial de computadores, onde se pode identificar um arsenal significativo de imagens, vídeos e textos sobre esses repertórios; o impacto das novas tecnologias de gravação, isto é, trata-se enfocar a transformação de certos tipos de Bumba-boi, Zulu Dancee Timbila emlugares da memória da nação, umprocesso de patrimonialização marcado por ambiguidades e desigualdades. O terceiro eixo investigação tem pretendido lançar um olhar sobre o mundo educacional e escolar. Tanto no Maranhão, a exemplo do que ocorre na educação básica do município de Alcântara, como em algumas províncias da região de Kwazulu-Natal na África do Sul (MELO, 2017; RODRIGUES, 2017) e em Moçambique (MOTA, 2015), sabe-se que algumas práticas escolares sebaseiam na experiência dessas manifestações culturais - Educação Patrimonial/Cultural. Assim, trata-se de focar os usos desses repertórios culturais em propostas educacionais, particularmente, aquelas relativas à construção de competências e habilidades de reconhecimento intercultural. 


\section{PATRIMONIALIZAÇÃO, EDUCAÇÃO E DESIGUALDADE NO BRASIL E NA ÁFRICA AUSTRAL}

Agenciada como símbolo e prática cultural fundamental para a construção da identidade nacional em Moçambique, território africano que conquista a sua independência e se constitui como um Estadonacional soberano em junho de 1975, depois deaproximadamente uma década de luta armada contra o colonialismo português (NEWITT, 1997), a Timbila, manifestação cultural característica dos chopi, um dos diversos grupos etnolinguísticos moçambicanos, seria, em 2005, proclamada pela UNESCO Obra-Prima do Patrimônio Orale Intangível da Humanidade. (WANE, 2010, BARROS, L., 2018).

$\mathrm{Na}$ África do Sul, esse movimento parece se intensificar a partir de 1994, quando, oficialmente, o Apartheid (POSEL, 1991) é substituído pela democracia, abrindo-se um processo de reinvenção da nação (COETZEE,1998; HARRIS, 2002; NUTTALL; COETZEE, 2002; BARROS, 2012a; 2016). Na perspectiva do Estado sul-africano, expressões de dança tais quais ingoma, indlamu, imvunulo e isicathamiya, bem como outros elementos culturais identificados como costumeiramente produzidos entre os zulus, seriam "[...] examples of symbols of national heritage" (DEPARTMENT..., 2010, p. 225), devendo ser patrimonializados. (BARROS, 2012a, 2016; MELO, 2017; RODRIGUES, 2017). Portanto, tratar-se-ia de elementos que deveriam ser vistos como bens culturais de grande relevância para a história, a memória e a identidade da Rainbow Nation - epíteto que se pretende seja gerador de uma nova sensibilidade nacional sul-africana, que deveria ser marcada pelos contatos entre diferentes e desiguais sujeitos de diversas origens étnicas. (BARROS, 2012a, 2016).

Os grupos de Bumba-meu-boi existem emtodas asregiões do Brasil. No Maranhão, há diferentes sotaques (tipos) de Bumba-boi: orquestra, costa de mão, zabumba ou matraca. Em geral, resultam de um pagamento de promessa feita a alguma entidade espiritual, sobretudo os santos docatolicismo, particularmente, SãoJoãoe São Pedro, mas também a entidades espirituais do tambor de mina (religião afro-brasileira) e da pajelança (religião afro-indígena e prática de medicina popular). Âs vezes, aquele que faz a promessa é o mesmo que organiza o bumba. Essa promessa pode passar de gera- 
ção a geração. Assim, preparando-se para as festas, cujo corolário, atualmente, é o mês de junho, os grupos se formam e ensaiam suas danças e toadas (músicas). Ummesmo agrupamento, compostopor homens, mulheres e crianças, pode ter um ou mais couros (bois), cuidadosamente nomeados, e também mais de um miolo. Este é o homem que pega o couro (representação do boi), coloca-o sobre o corpo e balança-o, dando-lhe ritmo. Enquanto isso, os brincantes, em diferentes funções, tocam matracas, pandeiros ou tambores erepetem em uníssono as toadas e canções do amo, o cantador e guia do bumba. Terminadas as festas, mata-se ritualmente o boi, uma ocasião de muitas dramatizações e encenações cômicas, realizada geralmente no mês de julho, até que no outro ano ele será ressuscitado e outra festa começa. (ALBERNAZ, 2004; SILVA; FERREIRA, 2008; FERRETTI, 2008; BARROS, 2007, 2010, 2012b).

Historicamente, as expressões de Zulu Dance são observadas em diferentes localidades da África Austral. Com o processo de independência da região e de instituição e superação do Apartheid, será sobretudo na África do Sul e, mais particularmente, na Zululândia, região que, em grande parte, coincide com o território de Kwazulu-Natal, que esse repertório cultural passará a ser, mais comumente, produzido. Geralmente, a Zulu Dance envolve homens e mulheres e é acompanhada por cantos vibrantes e às vezes pelo som de tambores, mas o principal apetrecho musical usado durante sua execução é a voz dos próprios brincantes. Na dança, homens e mulheres executam uma coreografia semelhante: ambos correm para frente e tentam erguer uma das pernas o mais alto possível, na tentativa deformar como corpoumângulo de 180 graus. (MELO, 2017).

A Timbila consiste numa forma de expressão cultural praticada, sobretudo, pelo povo chopi, particularmente na região sul de Moçambique. Emxitchopi, a língua local dos chopi, o prefixo ti designa o plural das palavras e mbila é o nome do xilofone artesanal fabricado e tocado de modo significativamente característico pelos chopi. Desse modo, timbila designa "[...] o nome dado ao conjunto de mbila que forma as orquestras típicas da região do distrito de Zavala (na província de Inhambane), queéconsiderado o seu berço, a terra dos chopi por excelência", e também "[...] o nome da dança que acompanha a música das orquestras." (WANE, 2010, p. 7-8), e, como manifestação cultural mais abrangente, a timbila "[...] engloba toda uma tradição oral expressa na poesia das suas canções que, por 
sua vez, cumprem uma importante função social na comunidade". (BARROS, 2018, p. 7-8).

Esses repertórios sociais de caráter cultural são produzidos e agenciados, sobretudo, por sujeitos e setores sociais subalternos - aos quais se têm, no passado e no presente, negado acesso à cidadania e até pertencimento à humanidade. De fato, constituem elementos e ocasiões privilegiados para se pensar processos e dinâmicas de mudança e transformação social, no contexto contemporâneo, levadosa cabo porhomens emulheres comuns deregiões periféricas de países em desenvolvimento, do sul do mundo, a exemplo do Maranhão, Kwazulu-Natal e Inhambane.

É significativo salientar que os universos da Zulu Dance, do Bumba-meu-boi e da Timbila apresentariam aquelas duas condições necessárias para se fazer comparações, já salientadas pelo historiador Marc Bloch desde os anos 1960: uma certa semelhança entre os fatos observados e uma certa dessemelhança entres os meios onde eles sãoproduzidos. (BLOCH, 1963). Defato, as políticas coloniais portuguesa e britânica instituíram e deixaram sequelas coloniais diversas na África do Sul, em Moçambique e no Brasil. Múltiplas foram as sensibilidades e culturas da diferença orquestradas nas relações entre europeus, nativos e africanos no território que se configuraria como Maranhão. (ASSUNÇÃO, 1999; BARROS, 2007, 2010, 2012b), entre os europeus e os diferentes povos, a exemplo dos zulus, do território que se tornaria a África do Sul. (JONGE, 1991; POSEL, 1991; FRY, 2003; STONE, 2008, MOUTINHO, 2010; BARROS, 2012a, 2016), bem como em Moçambique (FRY, 2003, ZAMPARONI, 2004).

Além disso, observa-se que constitui fenômeno global a transformação de determinados repertórios culturais, frequentemente aqueles outrora perseguidos e discriminados, em símbolos de um território. De fato, são exemplos desse processo o Bumba-boi. (MARQUES, 1999; REIS, 2000; CANJÃO, 2001; ALBERNAZ, 2004; BARROS, 2007, 2010, 2012b), a Zulu Dance (XULU, 2005; NDLELA, 2008; FIRENZI, 2012) e a Timbila (ROCHA, 1988; MUNGUAMBE, 2000; OLIVEIRA, 2008; WANE, 2010).

Elementos que têm sido objetos de interesse local e global desde fins do século XIX com as exposições universais ${ }^{2}$ até os dias atuais, como se pode notar em sites e blogs do mundo cibernético contemporâneo, Bumba-meu-boi, Zulu Dance e Timbila, particu- 
larmente ao longo do século XX, apesar de situados em contextos diferentes, passaram por um processo similar. Embora este tenha sido um movimento descontínuo e que precisa ser contextualmente situado, esses repertórios sociais passaram a ser identificados como elementos fundamentais do patrimônio cultural regional e nacional, que pertenceriam e deveriam ser preservados por todos, independentemente desuas diferençase desigualdades. Depráticas vistas como insólitas e opostas à boa ordem, à civilização e à moral, ocasião de violência, usos incômodos que representariam a barbárie e não uma almejada civilização, passariam a ser identificados como tradição da terra, espaços e manifestações da cultura e da identidade. De fato, estes movimentos se processaram em intensa aproximação com a busca de definição de cultura regional ou étnica, da cultura e daidentidade nacional.

Há, de fato, um campo vasto de possibilidades de aprofundamentoereflexãodoobjeto emanálise, especialmentena perspectiva de uma análise histórico-antropológica comparativa. Em primeiro lugar, através da análise de documentação referente ao Bumba-meu-boi, à Zulu Dance e a Timbila, particularmente, documentos oficiais referente às políticas culturais e registros e depoimentos de sujeitos produtores daquelas organizações culturais, é possível aprofundar a análise das relações entre política, cultura ecidadania em contextos diferentes. De fato, esses fenômenos vêm sendo enfocados por alguns estudos sobretudo de caráter antropológico. Empreendimentos analíticos que visem comparar tais fenômenos, talvez resultem na produção de interpretações originais das relações sociais e culturais no mundo contemporâneo. De um lado, pode-se dar atenção à produção artística daqueles que se envolvem com essas expressões culturais, bem como aos modos como esses repertórios vão sendo apropriados pelo estado e por outras instâncias de poder, e ainda sobre o modo como seus produtores redefinem suas formas de produzi-los e divulgá-los. De outro lado, podem ser descritos e analisados comparativamente os usos dessas manifestações culturais em propostas educacionais, particularmente, aquelas relativas à construção de competências e habilidades de reconhecimento intercultural. Isto se pode observar em programas educacionais do ensino básico de Kwazulu Natal, Moçambique e no Maranhão. Os órgãos estatais de cultura e educação e algumas escolas têminserido esses repertórios históricos de cultura e identidade no sistema escolar. Oficialmente, tratar-se-ia de um processo sistemático de trabalho educacional 
centrado no patrimônio cultural entendido como fonte primária de conhecimento. Em contato direto com as evidências e manifestações da cultura, os sujeitos compreenderiam o mundo através de um processo de valorização de sua herança cultural.

Emsegundolugar,épossível observaroprocessopormeiodo qual essas manifestações culturais têm sido, sobretudo a partir dos anos 2000, inseridos na contemporaneidade global, particularmente através da rede mundial de computadores. Atenta-se para o fato de que "[...] as profundas transformações na tecnologia da produção musical ocorridas nas últimas décadas provocaram uma alteração dramática do lugar que a música ocupa na sociedade e também para o indivíduo." (CARVALHO, 1999, p. 53). De fato, reconhece-se que os mecanismos de memória e de sua patrimonialização sãoprofundamente afetados pela popularização do computador, internet, celular, gravador digital, pen drive, fotografia digital, etc, (SMITH, 2006). Desse modo, entende-se que "[...] as novas tecnologias comunicacionais têm um profundo impacto na construção da memória e em sua articulação com o processo identitário." (SANSONE, 2012, p. 333).

De acordo com Trajano Filho (2012), existe uma “[...] tendência de redução semântica correlata ao processo que transforma instituições totais voltadas para a solidariedade, a reciprocidade e a convivialidade em ícones da cultura nacional - movimento necessariamenteanterior aos esforços explícitos eformais da patrimonialização". Em trabalho no qual enfoca as tabancas cabo-verdianas e as manjuandadis guineenses, Trajano Filho (2012, p. 38) argumenta que " $[\ldots]$ o processo formal de patrimonialização não nasce da pura decisão arbitrária doEstado. Ele éprecedido de umprocesso de pré-patrimonialização despoletado frequentemente por atores não estatais: pelos atores sociais locais e pela intelectualidade nacional". Certamente, "[...] o Estado entra nesse jogo somente quando ele já está bemadiantado e somente quando ele legitima expectativas institucionais" (TRAJANO FILHO, 2012, p. 38). Nessa perspectiva, nota-se que nos textos e contextos da patrimonialização oficial, há uma significativa redução semântica dos significados das expressões culturais, conformando um corpo homogêneo de sentidos. Em grande medida, como já observara Trajano Filho (2012), isto se dá porque essas práticas sociais, originalmente instituições totais, são transformadas em objeto cultural nacional para serem servidas no mundo do espetáculo e da cultura de massas; ao mesmo tempo, de- 
ve-se reconhecer que se foi possível que isto ocorresse, tal se deve em grande medida à ação de diferentes sujeitos, de dentro e de fora do Maranhão, de Inhambane e de Kwazulu-Natal.

De fato, deve-se salientar que é significativo o papel de setores e atores globais atuando na determinação dos processos de patrimonialização em África, a exemplo da Ảfrica do Sul (BARROS, 2012a, 2016) e de Moçambique. (WANE, 2010). Portanto, a criação de lugares de memória nos países africanos não seria o resultado de agendas puramente locais. Os processos de patrimonialização, de criação de lugares de memória, em África, estão profundamente relacionados a agendas internacionais (BARROS, 2012a, 2016; DE JONGE; ROWLANDS, 2007; TRAJANO FILHO, 2012).

Nessa perspectiva, explorando o universo da Timbila em Moçambique, através da análise de alguns documentos, especialmente, da obra Gentes Afortunadas, de Hugh Tavares Tracey (1903-1977), importante etnomusicólogo responsável por estudos acerca da chamada música tradicional da África meridional, Luciano Borges Barros (2018, p. 150) destaca que "[...] o processo de colonização não conseguiu apagar todas as expressões cognoscitivas, artísticas e políticas dos povos da região que, através da tradição oral e também escrita, reinventaram suas tradições, a exemplo da timbila". Borges Barros (2018) interpreta o trabalho de Tracey (gravações e descrições de Timbila nos anos 1930-1960) como parte de um processo que, para usar os termos de TrajanoFilho(2012), acabou se configurando como de pré-patrimonialização dessa modalidade expressiva. Assim, a obra de Tracey "[...] pode ser interpretada como um item da vasta biblioteca colonial, conjunto de saberes através dos quais África tem sido tornada dizível e visível. A intervenção de Tracey é situada num campo de invenção das tradições em um contexto colonial.” (BARROS, 2018, p. 4). Observa-se ainda que “[...] há profunda dificuldade de compreender radicalmente a timbila, posto que, geralmente, esse repertório social é interpretado a partir de categorias da análise social ehistórica ocidental", um contexto em que "[...] a Europa se define como normal, e o que não é europeu aparece como desordenado, anormal, primitivo". Finalmente, argumenta Borges Barros (2018, p. 150), que "[...] o processo por meio do qual atimbila passa a ser considerada como símbolodeidentidadenacional moçambicana ésimilar aoque ocorrecom outras expressões culturais emdiversos lugares do AtlânticoSul: processoambíguo, marcado por obliterações e tensões". Fatoéque "[...] através da timbila, 
oschopiapresentavamsua visãode mundo, criticandoe protestando contra o colonialismo e seus mecanismos, e tratando das múltiplas questões de seu cotidiano". (BARROS, 2018, p. 7, 77, 150-152).

Em estudo sobre as relações entreEstado, Cultura eNaçãona África do Sul pós-Apartheid, Inaldo Bata Rodrigues (2017) observara que, na recente história da África do Sul, o Estado tembuscado formular eimplementar políticas públicas no campo da cultura considerando a diversidade dos povos da região, momento que coincide com a África do Sul cujo sistema político formal é a democracia. Dessa forma, por meio de diferentes ações governamentais, busca-se promover uma série de políticas públicas visando à promoção e valorização da cultura, oque acaba se cristalizando na identificação de certos bens materiais e imateriais que são patrimonializados.

$\mathrm{Na}$ África do Sul pós-Apartheid, o primeiro projeto voltado para o campo da cultura data de 1994, efoi elaborado pelo Congresso Nacional Africano (ANC, na sigla em inglês), partido de Nelson Mandela, e acabou servindo de texto-base para a política nacional de cultura a partir de 1996. "Na construção das políticas culturais, que teve como base o projeto do ANC de 1994, os documentos dos organismos internacionais como a UNESCO foram ratificados pela África do Sul e seguidos para a construção dessa política pública." (RODRIGUES, 2017, p. 128-129). Observa-se que as formulações de "[...] políticas culturais elaboradas pelo estado sul-africano após 1994 pretendem oficialmente contribuir para a construção de uma nação multicultural e diversa". Nota-se que "[...] o patrimônio está a desempenhar uma dupla função: de construção da nação" e de sua inserção no campo do turismo, posto que "[...] os bens patrimonializados passam a fazer parte de rotas turísticas". Mas este é, antes de tudo, um processo complexo e marcado por tensões e ambiguidades. (RODRIGUES, 2017, p. 128-130).

Emseu estudo, África na sala de Aula na África: a reinvenção dos zulus, Aldina da Silva Melo (2017) enfoca os lugares sociais destinados à história e cultura zulu na África do Sul, do Apartheid ao pós-Apartheid. Sua pesquisa analisa tex tos eimagens sobre os zulus presentes nas coleções de livros didáticos de história intituladas History for Today, History in Action, Making History, Shuters History e Viewpoint History, usados na província sul-africana de Kwazulu-Natal. De acordo com a autora, pelo menos três questões devem ser destacadas quando se analisa esse material didático-escolar.Em 
primeiro lugar, "[...] o modo como a História se consagrou e se estruturou como ciência muito impactou na maneira como África foi representada durante muito tempo pelas narrativas historiográficas", inclusive na própria África, continente construído como lugar de não produção do conhecimento ou mesmo um '[...] 'não-lugar' no campo da História". Comos Estudos Africanos, passou-se a empreender um esforço de pensar o continente africano " [...] como local de produção de conhecimento e não mais como mero objeto de pesquisa europeia". Esse movimento de reconstrução da história e das sociedades em África “[...] ajuda a compreender as representações e o lugar destinado ao povo zulu na África do Sul seja durante o Apartheid, seja nas duas primeiras décadas do pós-1994."(MELO, 2017, p. 144-145).

Em segundo lugar,

A partir do estudo do lugar destinado à história e cultura zulu em dois períodos que marcaram profundamente a história da África do Sul - o Apartheid e pós-Apartheid - pode-se afirmar que: 1) o Apartheid não pode ser interpretado como um período da história sul-africana com um fim em si mesmo ou comoum acontecimento "linear", "perfeito" e "acabado" em si durante os 46 anos em que esteve oficializado; eistopode ser observadoa partir, por exemplo, das várias aprovações e revogações das leis segregacionistas; essas leis impactaram diretamente a vida cotidiana dos sujeitos sul-africanos [...] 2) O lugar, ou precisamente o "não-lugar", destinado aos zulus durante o Apartheid na sociedade sul-africana pode ser observado a partir da análise das narrativas textuais presentes nas coleções de livros didáticos de história adotados nesse períodopelas escolas em Johannesburg, Pietermatzburg e Durban - History for Todaye History in Action. Nessas coleções os zulus são representados como os "últimos outros" na África do Sul, ocupando o lugar da desordem, da barbárie, do caos, do atraso, do folclórico. (MELO, 2017, p. 144-145)

É significativo observar a ausência de elementos relativos ao conjuntoculturalzulu nos livros didáticos analisados por Melo. "De todos os 7 (sete) livros analisados de ensino de história, tênues ainda são as menções ao povo zulu, sua história e cultura, e as que há os resumem às narrativas sobre a ascensão de seu reino e a figura de Shaka". (MELO, 2017, p. 127). Embora Shaka tenha sido e ainda seja "[...] um grande símbolo da história e cultura zulu e da própria África do Sul", "[...] o que se questiona é o porquê de a história dos zulus ser apresentada apenas no livro da série 6 e 8 e nas demais 
séries haver um completosilenciamento sobre essepovo". (MELO, 2017, p. 127). Ademais, “[...] nos livros de história não são citados outros sujeitos na história dos zulus, como, por exemplo, as mulheres", que, defato, tinhamumpapel significativona culturazulu, bem como "[...] não são mencionadas as diversas expressões culturais desses sujeitos", como aZulu Dance, (MELO, 2017, p. 127), embora nos dias atuais esta expressão cultural seja relevante para as políticas públicas de turismo. (NDLELA, 2002; RODRIGUES, 2017).

Finalmente, ressalta-se "[...] asrupturas quepassarama ocorrer na África do Sul no modo de percepção dos zulus". (MELO, 2017, p. 145). Como o fim oficial do Apartheid, bem como com as transformações no campo da História e o avanço dos Estudos Africanos, "[...] mudanças começaram a ocorrer no próprio modo de percepção de África, dos africanos e na produção de conhecimento historiográfico". (MELO, 2017, p. 145). Assim, "[...] o povo zulu é reinventado na Rainbow Nation do governo de Nelson Madela". Apesar disso, embora sejam observadas "[...] rupturas na re(a)presentação dos zulus ainda permanecem certas continuidades no modo como a cultura zulu passou a ser apreendida pelos livros didáticos de história dopós-1994". Por exemplo, continua-sea usar otermotribo para se referir aos povos africanos e o termo nação para se referir aos povos europeus, nas coleções Making History, Shuters History e Viewpoint History. (MELO, 2017, p. 145).

O fato é que, conclui Melo (2017, p. 145-6), “[...] pode-se argumentar que os lugares sociais atribuídos a esses sujeitos foram teoricamente bem definidos e delimitados durante o Apartheid e, mesmo com as rupturas advindas com o pós-Apartheid, ainda hoje éperceptível a existência de hierarquias edesigualdades emrelação aos zulus nas práticas sociais locais, na África do Sul”. Observa-se, portanto, que

Mesmo com o fim oficial do Apartheid e com as mudanças ocasionadas no sistema educacional da África do Sul, bem como nos livros didáticos de história do pós-1994, ainda se faz necessário talvez alguns anos para que a disciplina de História possa superar os fantasmas das narrativas com as quais foi tecida a história dos zulus, para que, de fato, estes sujeitos com sua história e cultura deixem de ocupar olugar dos "últimos outros" na nação arco-íris. (MELO, 2017, p. 146). 
Cabe, finalmente, destacar que com o advento da nova constituição moçambicana em 1990, uma nova dinâmica começa a se estabelecer no plano das políticas culturais, "[...] já que há o reconhecimento da necessidade de valorização da diversidade cultural em Moçambique". Emalgumas regiões, "[...] modelos multiculturais e interculturais têm sido defendidos e, cada umao seu modo, entende que a escola e o sistema educacional deve reconhecer e fomentar a diversidade cultural". (MOTA, 2015, p. 67).

O fato é que o campo da cultura tem muito a dizer sobre as vidas e as concepções de mundo dos sujeitos produtores da cultura eainda sobre como o Estado nela pode intervir para reconstruir formas e sentidos de identidade étnica, regional e nacional.

\section{CONCLUSÃO}

O aprofundamento do estudo da produção e reprodução de repertórios culturais, numa perspectiva comparativa e cruzada Sul-Sul, poderá contribuir significativamente para a compreensão das dinâmicas que definem e caracterizaram as relações entre Estado, Cultura ePolíticas Públicas, inclusive podendo ajudar na definição das atuais políticas públicas destinadas aos setores e grupos sociais que demandam reconhecimento político e social através da defesa de suas expressões culturais.

Além disso, a promoção do bem estar social em territórios tão desiguais como aqueles do Maranhão, Inhambane e Kwazulu-Natal, dificilmente poderá se realizar se não se consideraremas especificidades culturais desses territórios. Não se trata da promoção da valorização folclórica dos bens culturais desses sujeitos, grupos e setores, mas do reconhecimento de que não se intervém no social semconsiderar ocultural, que só se compreendesituadonoprimeiro e que, muitas vezes, como têm largamente reconhecido as ciências sociais e humanas, as pessoas comuns pensam com coisas, com rituais, com comemorações, com festas, e com tudo aquilo que sua cultura coloca à sua disposição.

\section{REFERÊNCIAS}

ALBERNAZ, L. S. F. O "urrou" do boi em Atenas: instituições, experiências culturais e identidade no Maranhão. 2004. Tese (Doutorado em Ciências Sociais) - Instituto de Filosofia e Ciências 


\section{CULTURA, PATRIMONIALIZAÇÃO EDESIGUALDADE NO BRASIL E NA ÁFRICA AUSTRAL}

Humanas, Campinas, Universidade Estadual de Campinas, Campinas, SP, 2004.

APPIAH, K. A. Na casa de meu pai: a África na filosofia da cultura. Rio de Janeiro: Contraponto, 1997.

ASSUNÇÃO, M. R. Cultura popular e sociedade regional no Maranhão do século XIX. Revista de Políticas Públicas, São Luís, v. 3, n.1, p. 29-67, 1999.

BARROS, A. E. A. Ao ritmo dos Bumbas: obliterações e desigualdades na construção de um patrimônio festivo brasileiro (c. 1900-1950). In.: SANSONE, L. (Org.). Política do intangível: museus e patrimônios em nova perspectiva. Salvador: EDUFBA, 2012b.

As faces de John Dube: memória, história e nação na África do Sul. Curitiba: CRV, 2016.

As faces de John Dube: memória, história e nação na África do Sul. 2012. 205 f. Tese (Doutorado em Estudos Étnicos e Africanos) - Faculdade de Filosofia e Ciências Humanas, Universidade Federal da Bahia, Salvador, 2012a.

O Pantheon encantado: culturas e heranças étnicas na formação de identidade maranhense. 2007. 320 f. Dissertação (Mestrado em Estudos Étnicos e Africanos) - Faculdade de Filosofiae Ciências Humanas, Universidade Federal da Bahia, Salvador, 2007.

O processo de formação de "identidade maranhense" em meados do século XX. TOMO, Sergipe, n. 17, p. 183-231, 2010.

L. B. Na terra das "Gentes Afortunadas": Timbila, identidades e (re)produção cultural no universo chopi em Moçambique (c. 192050). 2018. 160f. Dissertação (Mestrado em História Social) - Centro de Ciências Humanas, Universidade Federal do Maranhão, São Luís, 2018.

BATES, R.; MUDIMBE, V. Y.; O’BARR, J. Africa and the Disciplines: the contribution of research in Africa to the social sciences and humanities. Chicago: University of Chicago Press, 1993.

BLOCH, M. Pour une histoirecomparée de sociétéseuropéennes. Mélanges Historiques, Paris, p. 16-40, t. 1., 1963.

CANJÃO, I. M. F. Bumba-meu-boi, o rito pede "passagem" em São Luís do Maranhão. 2001. Dissertação (Mestrado em Antropologia Social) - Universidade Federal do Rio Grande do Sul, Porto Alegre, 2001 . 
CARVALHO, J. J. de. Transformações da sensibilidade musical contemporânea. Horizontes Antropológicos, Porto Alegre, v. 5, n. 11, p. 53-91, out. 1999.

COETZEE, R. M. The mind of Apartheid. GeoRrey Conjré (1907-). Social dynamics, [S. 1.], n. 17, p. p. 1-35, 1991.

DEPARTMENT OF ARTS AND CULTURE. Review of Heritage Legislation. [S. 1. ], 2010.

FEIERMAN, S. African History and the dissolution of the World History. In.: BATES, R.; MUDIMBE, V.Y.; O’BARR, Jean. Africa and the Disciplines: the contribution of research in Africa to the social sciences and humanities. Chicago: The University of Chicago Press, 1993.

FERRETTI, S. F. Dimensões da Cultura: popular, erudita. Ciências Humanas em Revista, São Luís, v. 5, p. 39-54, 2008.

FIRENZI, T. The Changing Functions of Traditional Dance in Zulu Society: 1830-Present. Academic journal article from The International Journal of African Historical Studies, [S. 1.], v. 45, n. 3, 2012.

FRY, P. Culturas da diferença: sequelas das políticas coloniais portuguesas e britânicas na África Austral. Afro-Ásia, Salvador, v. 29/30, p. 271-316, 2003.

GLUCKMAN, M. Análise de uma situação social na Zululândia moderna. In.: FELDMAN-BIANCO, B. (Org.) Antropologia das Sociedades Contemporâneas: métodos. São Paulo: Global, 1987.

HARRIS, V. The Archival Sliver: Power, Memory, and Archives in South Africa. Archival Science, [S. 1.], v. 2, p. 63-86, 2002.

HAUPT, H. G. O lento surgimento de uma história comparada. In.: BOUTIER, J.; DOMINIQUE, J. (Orgs.). Passados Recompostos. Rio de Janeiro: FGV, 1998.

HOBSBAWN, E. Bandidos. Rio de Janeiro: Forense Universitária, 1976.

. Rebeldes primitivos: estudos sobre formas arcaicas de movimentos sociais nos séculos XIX e XX. Rio de Janeiro: Zahar, 1970.

HOUNTONDJI, P. Sur la philosophie africaine: critique de l'ethnophilosophie. Paris: F. Maspero, 1977. 
JONGE, K. de. África do Sul: apartheid e resistência. São Paulo: Cortez/EBOH, 1991.

LINDEN, M. van der. Doing comparative labour: some preliminaries. Transnaction - Labour History: Explorations. Ashgate, 2003.

LÖWY, M. Eric Hobsbawm, sociologist of peasant millenarianism. Estudos Avançados, São Paulo, v. 24, n. 69, p. 105-118, 2010.

MARQUES, F. E. de S. Mídia e experiência estética na cultura popular: o caso do Bumba-meu-boi. São Luís: Imprensa Universitária, 1999.

MBEMBE, A. As formas africanas de Auto-Inscrição. Estudos AfroAsiáticos, Rio de Janeiro, ano 23, n. 1, p. 171-209, 2001.

MELO, A. da S. África na Sala de Aula na África: a Reinvenção dos zulus. 2017. 206 f. Dissertação (Mestrado em História, Ensino e Narrativas) - Universidade Estadual do Maranhão, São Luís, 2017.

MOTA, J. G. Educação, Desigualdade e Diversidade em Moçambique. 2015. 65 f. Monografia (Licenciatura em Ciências HumanasSociologia) - Universidade Federal do Maranhão, Campus de Bacabal, Bacabal, 2015.

MOUTINHO, L. "Raça", sexualidade e gênero na construção da identidade nacional: uma comparação entre Brasil e África do Sul. Cadernos Pagu, Campinas, SP, n. 23, p. 55-88, 2004.

MUDIMBE, V. Y. The Idea of Africa. London: Britsh Library Cataloguing in Publication Data, 1994.

The invention of Africa: Gnosis, philosophy and the order of knowledge. Bloomington: Indiana University Press, 1988.

MunguAmBE, A. D. A Música Chope. Maputo: Promedia, 2000.

NDLELA, N. F. Representations of Zulu Cultural Identity in Cultural Tourism: a case study of Izintaba Zulu Cultural Village. 2008. $77 \mathrm{f}$. Mestrado (Master of Arts) - Cultural and Media Studies Programme, University of Natal, Durban, 2008.

. Representations of Zulu Cultural Identity in Cultural Tourism: a case study of Izintaba Zulu Cultural Village. 2002. $77 \mathrm{f}$. Mestrado (Master of Arts) - Cultural and Media Studies Programme, University of Natal, Durban, 2002.

NEWITT, M. História de Moçambique. Lisboa: Europa-América, 1997. 
NUTTALL, S.; COETZEE, C. (Orgs.). Negotiating the Past: the making of memory in South Africa. Cape Town: Oxford University Press, 1998

OLADIPO, O. The idea of African Philosophy: a critical study of the major orientations in contemporary african philosophy. 3. ed. Nigeria: Hope Publications, 2000.

OLIVEIRA, A. R. de. Monografias sobre as timbila e a construção do Império Português em Moçambique. 2008. 215 f. Mestrado (Dissertação em Antropologia Social) - Universidade Estadual de Campinas, Campinas, SP, 2008.

PESAVENTO, S. J. Exposições Universais: espetáculos da Modernidade do Século XIX. São Paulo: HUCITEC, 1997.

POSEL, D. The Making of Apartheid, 1948-1961. Oxford: Claredon Press: 1991.

REIS, J. R. S. dos. Bumba-meu boi: o maior espetáculo popular do Maranhão. 3. ed. São Luís: LITOGRAF 2000.

ROCHA, I. Um exemplo de resistência cultural. In: SEMANA DE CULTURA AFRICANA, 5., 1988, Coimbra. Actas... Coimbra: Instituto de Antropologia/Universidade de Coimbra, 1988. Moçambique: história e cultura de um país.

RODRIGUES, I. B. Estado, Cultura e Nação na África do Sul democrática. 2017. 138f. Dissertação (Mestrado em Políticas Públicas) - Universidade Federal do Maranhão, São Luís, 2017.

DE JONG, F.; ROWLANDS, M. Reconsidering heritage and memory. In.:_ ; (Ed.) Reclaiming Heritage: alternative imaginaries of memory in West Africa. Walnut Creek, CA: Left Coast Press, 2007.

SANSONE, L. (Org.). Política do intangível: museus e patrimônios em nova perspectiva. Salvador: EDUFBA, 2012.

SANTOS, B. de S.; MENESES, M. P. (Orgs.) Epistemologias do Sul. Coimbra: Gráfica de Coimbra, 2009.

SILVA, C. B. R.; FERREIRA, C. G. S. (Orgs.). Ritmos da Identidade Afro-Maranhense: boi de Zabumba. São Luis: EDUFMA, 2008.

SMITH, D. J. Cell Phones, Social Inequality, and Contemporary Culture in Nigeria. Canadian Journal of African Studies/Revue Canadienne des Études Africaines, [S. 1.], v. 40, n. 3, p. 496-523, 2006. 


\section{CULTURA, PATRIMONIALIZAÇÃO EDESIGUALDADE NOBRASIL}

E NA ÁFRICA AUSTRAL

L. T. Decolonizing Metodologies. Research and Indigenous Peoples. London; New York: Zed Book Ltd., 2001.

STONE, J. Retrato em preto e branco: a história verídica de uma família dividida por problemas raciais. São Paulo: Ed. Landscape, 2008.

THOMPSON, E. P. Costumes em comum: estudos sobre a cultura popular tradicional. São Paulo: Companhia das Letras, 1998.

TRAJANO FILHO, W. Patrimonialização dos artefatos culturais e a redução dos sentidos. In.: SANSONE, L. (Org.). Memórias da África: patrimônios, museus e políticas das identidades. Salvador: EDUFBA, 2012.

WANE, M. A Timbila chopi: construção de identidade étnica e política da diversidade cultural em Moçambique (1934-2007). 2010. Dissertação (Mestrado em Estudos Étnicos e Africanos) - Centro de Estudos Afro-Orientais, Universidade Federal da Bahia, Salvador, 2010

XULU, S. Gender, Tradition and Change: the role of rural women in the commoditization of zulu culture at selected tourist atrractions in Zululand. 2005. $155 \mathrm{f}$. Tese (Doutorado em Filosofia) - Department of Isizulu Namagugu, Universtity of Zululand, KwaDlangezwa, 2005.

ZAMPARONI, V.D. Entre Narros \& Mulungos: colonialismo e paisagem social em Lourenço Marques, c. 1890- c.1940. 1998. 580 f. Tese (Doutorado em História) - Faculdade de Filosofia, Letras e Ciências Humanas, Universidade de São Paulo, São Paulo, 1998.

A África e os estudos africanos no Brasil: passado efuturo. In.: Ciência e Cultura, São Paulo, v. 59, n. 2, apr./jun, 2007.

\section{Notas}

1 Este artigo, de caráter exploratório e que visa apresentar alguns resultados de pesquisa e, sobretudo, indicações para aprofundamento e reflexão, resulta da execução de dois projetos de pesquisa, quais sejam, Aoritmo de bumbase timbilas: patrimônio, cidadania e educação no Maranhão e em Inhambane (Moçambique), aprovado na Chamada Universal MCTI/ CNPQ N. 14/2013, e Dançando com Zulus e Chopis: Patrimônio, Cidadania e Gênero na África Austral, aprovado no âmbito da Chamada MCTI/CNPq/MEC/CAPES No 43/2013. Este texto antecipa, em parte, algumas das questões centrais que, serão aprofundadas, em livro homônimo, com previsão de publicação para 2019. Fundamentalmente, esta pesquisa, cuja perspectiva analítica é comparativa, tem como objeto o universo histórico e social do Bumba-meu-boi, da Zulu Dance e da Timbila no mundo contemporâneo, objetivando: reconstituir, comparativamente, particularmente, do terceiro terço do século XX aos dias atuais, práticas e representações instituintes do Bumba-meu-boi, da Zulu Dance, da Timbila, dando-se especial atenção às relações entre Estado e Cultura, eàs ações e formas 
de viver e interpretar o mundo, expressas nesses repertórios sociais por sujeitos e setores subalternos das regiões enfocadas; analisar comparativamente a relação entre política, cultura e cidadania no contexto brasileiro e moçambicano pós-independentes e sul-africano da segunda metade do século XX, do Apartheid à posterior democratização; analisar processos de revivescência cultural no universo da Zulu Dance, da Timbila e do Bumbameu-boi.; observar formas de construção da memória da naçãoe de patrimonizalização nos contextos sul-africano, brasileiro e moçambicano; descrever os usos do Bumba-meu-boi, da Zulu Dance e da Timbila em propostas educacionais, particularmente aquelas relativas à construção de competências e habilidades de reconhecimento intercultural; observar processos por meio dos quais essas manifestações de caráter cultural têm sido inseridas na contemporaneidade global, particularmente através da rede mundial de computadores.

${ }^{2}$ Grupos de Bumba-meu-boi do Maranhão, de Zulu Dance na África do Sul e práticas culturais relacionadas a Timbila em Moçambique foram levados para serem expostos nas exposições universais da Europa, que eram uma espécie de vitrines da modernidade realizadas entre o século XIX e primeiro terço do século XX. Nelas, pretendia-se oferecer grandes panoramas do poder do homem sobre o mundo, uma tentativa de abranger todo o conhecimento humano, organizá-lo e catalogá-lo. Enquanto os países desenvolvidos apresentavam a evolução técnica de suas nações, reforçandoa ideia da evolução embasada nas novas teorias biológicas e geológicas do século XIX, os ditos subdesenvolvidos, como o Brasil e regiões de Africa, tentavam impressionar tanto com seus esforços no campo industrial quanto com suas características exóticas, enviando para láalguns exemplares de seu folclore. Sobre as exposições universais oitocentistas, ver Pesavento (1997). 